\title{
Autonomia, saúde mental e subjetividade no contexto assistencial brasileiro*
}

\author{
Autonomía, salud mental y subjetividad en el contexto asistencial brasileño \\ Autonomy, Mental Health and Subjectivity in Brazilian Assistential Context
}

\section{Daniel Magalhães Goulart}

\section{Resumo}

Este estudo visa refletir teoricamente sobre formas de cuidado que priorizem o resgate da autonomia por parte de pessoas atendidas em serviços assistenciais de saúde mental no Brasil, enfatizando, sobretudo, o problemático período da alta institucional. Para tanto, faz-se uma apresentação das atuais mudanças no modelo assistencial em saúde no país e discute-se alguns princípios que norteiam a Reforma Psiquiátrica brasileira, atentando para a superação de impasses históricos e para as limitações das práticas institucionais, que ainda parecem culminar em frequentes quadros de institucionalização dos usuários. Nessa discussão, o estudo da subjetividade é apresentado como alternativa teórica para compreender como esses complexos e conflitantes processos se atualizam na vivência do sujeito.

Palavras-chave: autonomia, alta institucional, saúde mental, subjetividade, sujeito.

\section{Abstract}

This study aims to reflect theoretically on care ways that prioritize the rescue of autonomy by people assisted in mental health care services in Brazil, emphasizing specially in the problematic period of institutional discharge. With this purpose, the current changes in the health care model in the country are presented and some principles that guide the Brazilian Psychiatric Reform are discussed, paying attention to overcoming of historic impasses and to the limitations of institutional practices, that still seem to culminate in frequents cases of institutionalization of users. In this discussion, the study of subjectivity is presented as a theoretical alternative to understand how this complex and conflicting processes are updated in the subject's experience.

Keywords: autonomy, institutional discharge, mental health, subjectivity, subject.

- Fecha de recepción del artículo: 30-11-2012 • Fecha de aceptación: 23-01-2013

DANIEL MAGALHÃES GOULART. Mestrando pela Faculdade de Educação da Universidade de Brasília (FE-UnB) com bolsa CAPES; Psicólogo pela Universidade de Sáo Paulo; Bacharel Especial em Pesquisa pelo Departamento de Psicologia da Faculdade de Filosofia, Ciências e Letras de Ribeirão Preto da Universidade de São Paulo (FFCLRP-USP). Brasília/DF, Brasil. Correio eletrônico: danielgoulartbr@yahoo.com.br

\footnotetext{
Este artigo é derivado da pesquisa do autor no Mestrado Acadêmico em Educação, pela Universidade de Brasília (FE-UnB), dentro da linha de pesquisa "O sujeito que aprende, processos de aprendizagem e saúde", coordenada pelo Prof. Dr. Fernando González Rey. A pesquisa é financiada pela Coordenação de Aperfeiçoamento de Pessoal em Nível Superior (CAPES), teve início em março de 2012 e tem término previsto para fevereiro de 2014.
} 


\section{Resumen}

Este estudio tiene como objetivo reflexionar teóricamente sobre las formas de cuidado que priorizan el rescate de la autonomía de las personas atendidas en los servicios asistenciales en salud mental en Brasil, enfatizando, sobretodo, el período problemático de alta institucional. Para llevar a cabo lo anterior, se hace una presentación de los cambios actuales en el modelo de asistencia de salud en el país y se discuten algunos de los principios que guían la Reforma Psiquiátrica Brasileña, haciendo énfasis en la superación de impases históricos y en las limitaciones de las prácticas institucionales, que aún parecen culminar en frecuentes casos de institucionalización de los usuarios. En esta discusión, el estudio de la subjetividad es presentado como alternativa teórica para entender cómo esos complejos y contradictorios procesos se actualizan en la vivencia del sujeto.

Palabras clave: autonomía, alta institucional, salud mental, subjetividad, sujeto.

\section{Introdução}

\section{Sistema Único de Saúde (SUS) brasileiro e suas contradições}

As concepçóes de saúde mental e as formas de lidar com seus desdobramentos passaram por várias transformaçōes ao longo dos anos no Brasil. De uma lógica asilar ou manicomial, enclausurando os ditos "doentes mentais" em instituições fechadas (muitas vezes vitaliciamente), passamos atualmente por uma tentativa formalizada de ampliação do olhar e da atençáo prestada a essas pessoas.

Esse processo de mudança acompanhou transformaçôes sociais ainda mais amplas, culminando na instituição do Sistema Único de Saúde (SUS) em 1990, com base nas prerrogativas de um Estado democrático e de cidadania plena, determinantes de uma "saúde como direito de todos e dever do Estado" (Brasil, 2004ª , p. 13). O SUS é filiado à tradição das políticas públicas e, nesse sentido, concebido como um sistema de proteçáo social. Trata-se de uma rede de serviços e um conjunto de normas destinado a toda sociedade e náo apenas a determinados setores sociais (Campos, 2006).
Esse sistema é alicerçado sobre os princípios da universalidade no acesso aos serviços de saúde; da integralidade das açôes, de modo a respeitar o indivíduo em sua totalidade; da equidade, visando à mesma garantia desse direito a todos, de modo a respeitar suas diferenças; da descentralização dos recursos de saúde, com a garantia de serviços prestados de qualidade e o mais próximo possível que deles necessitam; e do controle social, a ser exercido pelos Conselhos Municipais, Estaduais e Nacional de Saúde, com a participação dos usuários, profissionais dos serviços, diversas organizaçôes da sociedade civil, trabalhadores e instituiçóes formadoras (Brasil, 2004a).

Essas transformaçóes se deram a partir de intensa mobilização social, em reivindicaçôes por mudanças nas formas de lidar com a saúde pública, buscando dessa forma, maior humanização nas relações desenvolvidas dentro das instituiçóes de saúde. $\mathrm{O}$ modelo hegemônico vigente mostravase insuficiente para atender essa demanda e suas transformaçóes deveriam necessariamente ocorrer sobre outras bases.

O SUS emerge fortemente influenciado pelo Movimento de Reforma Sanitária, enquanto contraponto à tendência hospitalocêntrica, possuindo, assim, caráter inovador, "com foco na prevenção, descentralização e uma expectativa de participação popular associada" (Nascimento, 2009, p. 26). Ainda que esses objetivos não sejam fáceis de serem alcançados, como bem aponta o autor previamente citado, percebe-se uma abertura inédita à incorporação do "popular" na construção de suas políticas. Isso contraria, de certo modo, a tendência neoliberal assistida no cenário mundial, sobretudo a partir dos anos 1990, marcada pela enorme influência dos grandes grupos privados internacionais, sob a fachada ilusória do mercado livre.

Nessa perspectiva, muitos avanços têm sido observados nessa pluralidade de sentidos, náo apenas assegurando a universalização do direito à saúde, mas também no respeito às diferenças culturais e no controle social pela reforma, garantindo que esse processo não se dê de forma homogênea, autoritária e contrária aos grupos antes excluídos (Fleischer, Tornquist, \& Medeiros, 2009).

Entretanto, percebe-se que muito ainda há que se percorrer para que suas premissas sejam efetivamente desenvolvidas em nosso cotidiano. 
Nesse sentido, não é porque o SUS foi legalmente instituído, mediante propostas inovadoras, que ele seja politicamente executado em sua plenitude. Concordando com Campos (2006), os diversos entraves políticos e a falta de amadurecimento da sociedade civil contribuem bastante na falta de aperfeiçoamento e funcionamento regular do sistema. Seria como se a legislação do SUS fosse mais generosa que o Brasil real.

Nascimento (2009) aponta para os entraves políticos desse processo, culminando numa situação atual crítica que merece ser debatida. Segundo o autor, a partir das leis orgânicas da Saúde de 1990, que consolidaram a implementação do SUS, assistiu-se à excessiva centralização do poder sobre as diretrizes para a saúde no âmbito do poder Executivo, culminando na fragilização das propostas, na medida em que a política para assistência à saúde ficou mais vulnerável às pressóes dos grupos privados com interesse nessa esfera, resultando na crescente importância política dos planos de saúde privados no país. Esse processo acabou dando origem à configuraçáo atual da política nacional voltada à saúde, caracterizada por um mix público-privado. Desse modo, poucos anos após a implantação do SUS, vê-se o desenvolvimento da lógica da nova universalidade (Gershman, $\&$ Santos, 2006), atuante no período marcado pelo desenvolvimento do Programa de Saúde da Família. Essa lógica consiste, por um lado, no fomento de um pacote básico de serviços para a Rede Básica de Saúde, concentrando recursos para as camadas da sociedade com menor poder aquisitivo e, por outro, no favorecimento da expansáo dos grupos privados de assistência à saúde, em serviços não cobertos no pacote essencial preconizado pelo Estado.

Assim, ainda que com inovaçóes importantes na implementação do SUS e conquistas inéditas para a saúde pública do país, o Brasil parece estar escrevendo, por linhas diferentes, um desfecho semelhante ao que se viu acontecer em boa parte do mundo: a ampliação exorbitante dos lucros privados, em detrimento do desenvolvimento de um panorama de assistência à saúde segundo os três principais fundamentos ratificados há mais de 20 anos: universalização, integralidade e equidade.

Não obstante, mediante implementação do SUS, houve melhoria crescente no controle da mortalidade infantil, na esperança de vida dos brasileiros e no controle e erradicação de epidemias e endemias no país (Brasil, 2004b). Coloca-se como hipótese, neste estudo, que dentre outros fatores envolvidos, essas melhorias podem ser desdobramentos do fortalecimento da Rede Básica de Saúde no país, que é constituída pelas unidades de saúde locais e regionais e também pelo Programa de Saúde da Família e de Agentes Comunitários de Saúde, que tem atuaçáo no território a que se remetem. Essa Rede é caracterizada pelo desenvolvimento de açóes voltadas para a promoçáo e proteçáo de saúde, diagnóstico, prevenção de agravos, alguns tratamentos e reabilitação. A bem dizer, a Rede Básica de Saúde focaliza as questôes mais frequentes da populaçáo, trabalhando na reduçáo de danos e do sofrimento, almejando a conquista de uma melhor qualidade de vida por parte das pessoas acompanhadas. Desse modo, "o foco da atenção é a pessoa, e não a doença” (Brasil, 2009, p. 16). Visando uma atenção longitudinal, envolvendo a convivência numa duração, pode-se dizer que a Rede Básica de Saúdeapóia suas açôes nos vínculos construídos com as pessoas acompanhadas.

Uma figura que emerge com força no cenário da Atenção Básica é a do "agente comunitário de saúde" (ACS). Segundo Peres, Junior, Silva e Marin (2011) o ACS é personagem-chave na organização da assistência em saúde no Brasil, uma vez que assume uma posição bidirecional, sendo morador da comunidade em que trabalha e, ao mesmo tempo, integrante da equipe de saúde. Seu principal objetivo no trabalho é favorecer uma melhor qualidade de vida para as pessoas e comunidades atendidas. Cohn, Nakamura e Gutierres (2009) apontam para o caráter ambíguo desse trabalho, alternando entre os polos da normatização e da emancipação. Ele é, simultaneamente, "da saúde" e "da comunidade". Seu trabalho, sobretudo as visitas domiciliares realizadas, oferece à assistência em saúde um grau elevado de capilaridade social, aumentando os tentáculos do Estado, mas carregando também um teor privado nas relaçóes pessoais desenvolvidas. Os ACS cumprem, assim, um papel de mediador entre as esferas públicas e privadas da vida social. Nesse sentido, pode-se dizer que há um lado estratégico na maior capilarização social do trabalho do Estado, isto é, um maior controle do poder público sobre a vida privada. Não obstante, ele é feito pelo trabalho de uma pessoa que também é 
da comunidade atendida e, portanto, a ação de controle carrega em si a potencialidade de associação a outras açóes que estejam vinculadas a uma maior autonomia da própria comunidade. As autoras, nessa argumentação, revelam com profundidade a contradição desse trabalho, que, entretanto, é sua condição de maior alcance. $\mathrm{O}$ trabalho dos ACS e o vínculo das pessoas da comunidade com os mesmos representam uma diferença qualitativa importante na dimensão do cuidado e na concepção de saúde, de modo geral. Acredita-se que resida aí um importante alcance do SUS e um fato para suas conquistas até então, na medida em que há uma flexibilizaçáo da atençáo prestada, dando mais possibilidades do serviço de saúde ir ao encontro das necessidades pessoais na comunidade, potencializando recursos próprios, ainda que isso implique eventualmente na correção de alguns hábitos e no oferecimento de modelos para outros. Destaca-se que assumir a relevância desse trabalho é também assumir o papel fundamental da educaçáo - no sentido amplo do termo- implicado na saúde. Pode-se dizer que a lógica de trabalho do PSF, ao menos em termos ideais, assume um caráter de construção dos profissionais em conjunto com a população e não em uma lógica de que os profissionais são detentores do saber, que oferecem respostas às pessoas ignorantes.

Por garantir uma função estratégica e central no SUS, a rede básica de saúde extrapola seus limites e acaba por atuar também nos cuidados especializados, como por exemplo, na saúde mental; daí a importância dessa discussão para $o$ interesse central deste estudo. $\mathrm{O}$ trabalho não mais é preconizado somente dentro dos serviços de saúde mental, mas prevê a articulação fundamental com a rede básica de saúde e, por consequência, com os ACS. Entende-se, portanto, que há, no SUS, uma brecha importante para que a lógica asilar não se faça presente, ou ao menos, não se faça predominante. Os cuidados às pessoas com severos transtornos mentais abre mão de sua característica historicamente hermética, para ganhar a capilaridade social descrita acima. Assim, seriam os recursos do próprio serviço de saúde pública que se responsabilizariam, também, pela promoção da autonomia das pessoas atendidas.

\section{0 dispositivo "CAPS" no âmbito da Reforma Psiquiátrica no Brasil}

Nesse contexto permeado por tantas contradiçóes também pode ser compreendido o movimento da Reforma Psiquiátrica no país. Esse movimento consiste no gradual e progressivo deslocamento do centro do cuidado em saúde mental para fora do hospital, em direção à comunidade, num processo de desinstitucionalização da pessoa em sofrimento psíquico (Brasil, 2010).

Vale ressaltar que a desinstitucionalização - categoria central desse movimento- emerge, também, enquanto conceito fundamental deste estudo, na medida em que representa a consideração pelas múltiplas relaçóes da pessoa, respeitando a lógica vivencial do seu contexto de vida. Não há possibilidades, mediante esta perspectiva, de isolar o indivíduo em determinado espaço social que não lhe corresponde. O que está implícito é uma nova configuração de poderes, em que a pessoa é levada em conta enquanto sujeito da relação, impossibilitando que a complexidade de sua vida seja solapada de maneira arbitrária. Tal noção parece um norte interessante para transformaçóes no âmbito da saúde. Não obstante, talvez pela subversão que ela implica, ainda permanece algo bastante difícil ser conquistado, como será mais detalhado adiante.

O movimento da Reforma Psiquiátrica inicia-se a partir da contestação da perspectiva medicalizante do sofrimento psíquico, visando uma dissolução das barreiras rígidas entre assistentes e assistidos, promovendo a liberdade por meio de mecanismos que consideram o usuário como sujeito de sua existência (Teixeira Junior, Kantorski, \&Olschowski, 2009). Nessa perspectiva, a eclosão dos movimentos da Reforma Psiquiátrica brasileira colocou em debate a dimensão epistemológica da psiquiatria, ou seja, suscitou discussōes sobre o campo teórico-conceitual que fundamenta e legitima o saber/fazer médico-psiquiátrico (Ramos, Guimarães, Enders, 2011). De acordo com Amarante (2009), o maior objetivo desse processo não se coloca na mera transformação do modelo assistencial, mas sim na transformação do lugar social da loucura, da diferença e da divergência.

A rede básica de saúde seria o lugar privilegiado para a construçáo de uma nova lógica de atendimento e de relação com pessoas com transtornos 
mentais, de forma que os CAPS seriam os dispositivos estratégicos desse movimento. Na definição oferecida pelo Ministério da Saúde do Brasil,

Os CAPS são instituiçóes destinadas a acolher os pacientes com transtornos mentais, estimular sua integração social e familiar, apoiá-los em suas iniciativas de busca da autonomia, oferecer-lhes atendimento médico e psicológico. Sua característica principal é buscar integrá-los a um ambiente social e cultural concreto, designado como seu "território", o espaço da cidade onde se desenvolve a vida quotidiana de usuários e familiares. Os CAPS constituem a principal estratégia do processo de reforma psiquiátrica. (Brasil, 2004 $4^{\mathrm{a}}$, p.9).

Nesse sentido, o CAPS é concebido como um serviço que busca as potencialidades dos recursos comunitários à sua volta, de modo que todos esses recursos estejam incluídos na assistência especializada em saúde mental. Assim, a reabilitação social pode até se dar a partir do CAPS, porém necessariamente sempre em direção à comunidade.

\section{Apresentando a questão}

A partir da formalizaçáo dessas transformaçóes, enquanto políticas públicas estruturadas pôde-se assistir a importantes avanços na assistência à saúde mental, levando à problematização e parcial superação de impasses até entáo insolúveis. Ademais, essas mudanças suscitaram debates em diversas esferas sociais, culminando num processo interessante de reflexão sobre novas possibilidades de convivência em meio às diferenças sociais - o que levou a diversos questionamentos sobre as diversas formas de exclusão que pautavam sobremaneira a sociedade brasileira até entáo. Teixeira Junior, Kantorski e Olshchowski (2009), em estudo realizado sobre as vivências dos usuários no CAPS e a importância que estes atribuem à atenção psicossocial, analisaram que os relatos de usuários que vivenciaram a mudança do modo asilar para o psicossocial permitem interpretar que o CAPS, a partir de suas estratégias, significou um lugar de experimentação para a concretização de práticas geradoras de sentido e produtoras de vida.

Também a partir de análises elaboradas com base em entrevistas, Pande e Amarante (2011) argumentam sobre alguns avanços significativos da assistência prestada aos usuários no CAPS, em comparação ao tratamento no hospital psiquiátrico: a diminuição da frequência e do tempo das internaçôes, melhor qualidade dos serviços prestados e menor hierarquização na relação entre técnicos e usuários. Os autores também apontam para a grande diferença nos ideais de cuidado do CAPS, em relaçáo aos manicômios, de modo que práticas muitas vezes cruéis foram substituídas por uma espécie de proteção dos profissionais em relação aos usuários. Todavia, em muitos casos, a manutenção dos usuários no serviço, justificada por essa proteção, seria um desdobramento de certa infantilização atribuída a eles, culminando, por fim, em sobrecarga e dependência destes em relação ao serviço.

Acredita-se que esse fator dificulte em grande medida um alcance mais pleno daquilo que foi discutido acima enquanto desinstitucionalização. Nesse caso, conforme aponta Rotelli, Leonardis e Mauri (2001), estaríamos mais próximos, na realidade, de um processo de desospitalizaçáo, que, no entanto, guarda diversas características da lógica manicomial, sobretudo, no que se refere ao favorecimento da dependência do usuário em relação ao serviço - o que os autores nomeiam de nova cronicidade.

Uma manifestaçáo altamente incidente desse quadro na realidade dos CAPS - e que se propõe a analisar com mais detalhes neste estudo - é a permanência de alguns usuários nas atividades terapêuticas da instituiçáo por diversos anos, contrariando a idealização dos CAPS, enquanto serviços "de passagem" e que não desenvolvam a dependência do usuário e que ajudem no processo de reconstrução de laços sociais, familiares e comunitários, com vistas à autonomia gradativa da pessoa atendida (Brasil, 2004a). Em muitos casos, usuários mantém por anos a fio o CAPS como único espaço social em que são mantidas relaçóes pessoais e atividades fora de casa. Nesses casos, a cronificação do usuário parece se dar de forma inevitável e o papel emancipatório a ser cumprido pela instituição se vê comprometido em grande medida.

Outro agravante que parece ser agravante para a manutenção desse quadro, dificultando a potencialização dos alcances dos CAPS é a confusão e a coexistência dos princípios norteadores da Reforma Psiquiátrica com concepçóes e práticas 
ainda cristalizadas do paradigma hospitalocêntrico, o que, de acordo com Lucchese e Barros (2009), pode ser um desdobramento da formação dos profissionais ainda calcada no antigo modelo de assistência à saúde. As autoras destacam o impasse de náo se priorizar a criatividade e a responsabilidade na formaçáo do profissional e depois se exigir do mesmo autonomia e inovação no cuidado com o outro. Nesse sentido, Rosa e Lustosa (2010) argumentam sobre a necessidade de enfrentarmos a fragmentação do saber, assumindo um exercício de crítica permanente e capaz de avaliar os limites e as possibilidades da formação profissional na atualidade.

Dentro desse panorama discutido até o momento, o presente estudo se coloca favorável aos princípios do movimento da Reforma Psiquiátrica, que parecem estar afinados às transformaçōes que norteiam a implementaçáo do SUS no Brasil, conforme se explicitou acima. No entanto, pelos desafios atuais que esse movimento enfrenta, faz-se relevante a discussão de novas possibilidades para a superaçáo de impasses ainda marcantes em seu desenvolvimento. Nesse sentido, propóe-se enquanto objetivo central deste estudo refletir teoricamente sobre modos alternativos de se pensar cuidados mais favorecedores de autonomia por parte das pessoas atendidas, enfatizando, sobretudo, o problemático período de gradual afastamento por parte do usuário do CAPS.

\section{Discussão}

\section{Extrapolando os limites institucionais na criação de novas alternativas}

Como apontado anteriormente, questóes de múltiplas naturezas estão implicadas na culminância do crítico cenário que assistimos atualmente. Muitas vezes, a falta de vontade política, a partir dos múltiplos jogos de poder vigentes, é significativa barreira para mudanças mais efetivas e rápidas. A manutenção de uma formação para o trabalho em saúde mental ainda calcada no modelo hospitalocêntrico também parece colocar um desafio em âmbito nacional. No entanto, pode-se pensar que a partir da conjuntura já existente, talvez se pudesse potencializar transformaçóes que não estáo se dando na prática institucional. $\mathrm{O}$ que estaria dificultando essas transformações?
Nessa discussão, Bichaff (2006) argumenta que, ainda que as estratégias traçadas pela equipe estejam alinhadas aos princípios propostos para os serviços CAPS no que se refere aos cuidados assistenciais dos usuários, elas se encontram distanciadas quando se trata das práticas de inclusão social e territoriais. Nesse mesmo sentido, Pande e Amarante (2011) fazem referência a essa necessidade dos CAPS buscarem ações mais integradas ao território, de modo a evitar uma centralização da busca por recursos terapêuticos nas próprias atividades ou açóes do serviço. Isso favoreceria o exercício da autonomia dos usuários, evitando o risco da produção de novas formas de cronicidade ou institucionalizaçáo. No entanto, a partir de entrevistas realizadas no referido estudo, os autores encontraram que, em grande parte das vezes, essas ações em conjunto com a sociedade são relegadas a iniciativas individuais, ao invés de terem um caráter estratégico coletivo.

Acredita-se, neste estudo, que tal limitação dos serviços repercuta sobremaneira na dificuldade dos CAPS em dar alta para usuários já em condiçóes de fazer acompanhamento em outras instâncias de rede de saúde. Essa situação, somada à grande demanda por assistência em saúde mental da população, culmina em frequentes quadros de inchaço dos serviços - o que, inevitavelmente compromete a qualidade da assistência oferecida, bem como a qualidade das relaçóes tecidas nesses contextos.

O processo de gradual afastamento do CAPS por parte do usuário é aqui considerado como uma etapa fundamental na retomada da autonomia e na reabilitaçáo social da pessoa atendida. Tratase de um processo delicado, que pode exigir o enfrentamento de inúmeros desafios, tais como: a conquista da independência dos frequentes recursos terapêuticos institucionais, a retomada de um vínculo empregatício no mercado de trabalho, o enfrentamento de preconceitos diversos em relação ao transtorno mental, maior tempo de convivência com os familiares e a inserção em outras redes sociais. Trata-se, também, de um momento sensível para refletir sobre a lógica de assistência nesse âmbito da saúde pública, sendo crucial para se compreender os alcances e limites institucionais que atuam nesse processo. Nesse sentido, uma questão parece pertinente nessa discussão: de que modo o acompanhamento realizado nesse momento pelos profissionais do serviço pode 
facilitar a promoção de autonomia desses pacientes em suas vidas?

Percebe-se em alguns serviços de saúde um processo de naturalizaçáo das relaçóes terapêuticas, de modo que o papel de doente mental relegado pelo profissional ao usuário se cronifica. (Pande, \& Amarante, 2009; Rotelli,Leonardis, \& Mauri, 2001). Assim, a despeito das estratégias terapêuticas adotadas, há certa passividade na espera que esses pacientes melhorem e conquistem alta por eles mesmos. O que fica evidente em alguns casos é a existência de uma rigidez na configuração institucional, que espera o paciente se adequar aos seus padróes de relaçôes e serviços, ao invés do esforço de ir ao encontro das necessidades individuais de cada pessoa atendida. Por que será que isso acontece?

Sobre essa questão, são levantadas duas hipóteses:

A primeira é que a atenção voltada para as diversas atividades terapêuticas desenvolvidas não dá a ênfase necessária no caráter emancipatório do tratamento. Isto é, percebe-se certa carência de estratégias consistentes que visam o resgate da autonomia dos usuários e que auxiliem no gradual afastamento do serviço.

De acordo com Campos e Amaral (2007), o fazer clínico que se propóe à flexibilizaçáo diante da heterogeneidade dos casos concretos atendidos deve se basear na reconstruçáo permanente do seu trabalho, segundo o que os autores chamam de neo-artesanato. Nessa perspectiva, a finalidade do trabalho clínico se altera substancialmente, ao enfatizar a produção de saúde, ampliando o grau de autonomia dos usuários. Concordo com a concepção de autonomia dos autores enquanto "um conceito relativo, náo como a ausência de qualquer tipo de dependência, mas como uma ampliação da capacidade do usuário de lidar com sua própria rede ou sistema de dependências" (Campos, \& Amaral, 2007, p. 852).

Com efeito, ao falar de autonomia, neste estudo, não se remete a uma condição a ser alcançada apenas por usuários com determinadas características "mais autônomas" do que outros. Também, não é desconsiderado o desafio de compreender as dificuldades e tentar ampliar as possibilidades referentes às condiçóes de trocas sociais constantemente permeadas por preconceitos, discriminação e normatizaçáo da vida social. Como aponta Guerra (2004, p.88), a idéia não seria potencializar uma reabilitaçáo psicossocial que "subtrai o sujeito em nome de uma lógica produtiva maior que aquele", mas que leve em consideração a dimensão política e social desse processo, em termos da capacidade contratual de cada sujeito. Nesse sentido, considera-se impossível falar de reabilitação social, no sentido de voltar a uma condição anterior ao transtorno mental, numa pretensa tentativa de negar os inúmeros desdobramentos dessa experiência para a vida da pessoa. O que se acredita ser possível é favorecer, mesmo diante de intensas dificuldades e sofrimento, que o sujeito emerja na potencializaçáo de seus próprios recursos, com vistas à criação de novas possibilidades de se estar no mundo. Ainda nas palavras de Guerra (2004, p. 93): "Há sempre uma possibilidade de construçáo de resposta por parte do sujeito, mais ou menos precária, mais ou menos capaz de provocar enlaçamentos. Seguir essa resposta tomando-a como marca do estilo do sujeito nos ensina também que, por ela, o sujeito é sempre responsável”.

A segunda hipótese levantada, intensamente relacionada à primeira, é que a formulação dessas estratégias que visam o resgate da autonomia dos usuários, quando existentes, não leva em conta o potencial educativo presente nas relaçóes terapêuticas estabelecidas no serviço. Como destaca González Rey (2009a), uma experiência possui caráter educativo quando favorece o desencadeamento de novas reflexóes, reaçóes e emoçóes entre os participantes desse processo, de modo a estimular que eles assumam uma posição ativa dentro de um espaço social constituído por um caminho de troca, crítica e reflexão, no qual se desenvolvem tanto as pessoas implicadas, como o espaço social em questão. Desse modo, potencializar os aspectos educativos do trabalho terapêutico, especialmente no momento do gradual afastamento da instituição, implica na abertura a ouvir a pessoa atendida e criar estratégias com base no diálogo estabelecido, de modo a incluir o usuário enquanto partícipe fundamental da construçáo do próprio tratamento, saindo da posição de quem apenas é governada pelos "detentores do saber".

Acredita-se que uma forma viável de promover esse processo seja oportunizar um acompanhamen- 
to do usuário não apenas dentro da instituição, mas também em outros espaços sociais que fazem ou podem vir a fazer parte de sua vida, como associaçóes esportivas, grupos populares de artesanato, canto, dança etc. Nas palavras de Duarte (2011, p. 223), "o cuidado no processo de desinstitucionalização exige articulação da rede comunitária de cuidados e profissionais capazes de superar o paradigma da tutela do louco e da loucura”. Uma profícua e indispensável forma dessa articulação se dá ao envolver profissionais do CAPS e do serviço de atenção básica de referência em trabalhos conjuntos, visando a potencialização de recursos. Concordando com Pitiá e Furegato (2009), a responsabilização pelas equipes de saúde da família em relaçáo ao acompanhamento adequado do usuário com intenso sofrimento psíquico tem desdobramentos muito positivos, na reintegração social e na promoção de saúde.

Ao falar dos aspectos educativos atuantes (ou potencialmente atuantes) nesse processo, não se está se remetendo aos modelos calcados na aprendizagem de determinadas habilidades e manutenção de repertórios comportamentais que facilitem a adequação do indivíduo à sociedade (Guerra, 2004), mas numa concepção de aprendizagem enquanto prática dialógica, que preconiza o caráter singular desse processo para cada sujeito, de modo que este só se desenvolverá na tensão de sua produção pessoal ante a possibilidade de alimentar com suas experiências o que aprende e de alimentar também o seu mundo com aquilo que aprende (González Rey, 2008). Para tanto, considera-se ser fundamental conhecer e compreender quem são estas pessoas atendidas pelas instituiçóes de saúde mental, quais são seus saberes, o que valorizam, de que forma se relacionam etc. É importante, sobretudo, que haja abertura por parte da equipe de profissionais para repensar e reelaborar a estratégia terapêutica, com base no que o usuário traz, nesse contato, como significativo para si.

\section{0 estudo da subjetividade como alternativa teórica nas pesquisas em saúde mental}

Ambas as hipóteses tecidas acima culminam num ponto comum, sem o qual novas estratégias institucionais com vistas à autonomia dos usuários parecem estar fadadas ao fracasso: a importância de se conhecer as formas como a pessoa atendida organiza a própria experiência, mediante sua produção emocional. Residiria aí importantes entraves e potencialidades para o desenvolvimento pessoal $\mathrm{e}$, consequentemente, o fundamento de limites e alcances do tratamento propostos nos serviços de saúde mental. Desse modo, alternativas teóricas e metodológicas se fazem necessárias para essa busca, de modo que, nesta parte final do trabalho, dedicar-se-á em apresentar, brevemente, a Teoria da Subjetividade e alguns de seus desdobramentos epistemológicos, enquanto uma dessas possibilidades discutidas atualmente e que se mostra interessante para o contexto em pauta. Segundo Mitjáns Martinez (2005), a Teoria da Subjetividade busca dar visibilidade à complexidade do psiquismo humano, a partir de uma perspectiva histórico-cultural, de modo que seu corpus teórico se apresenta na definiçáo e articulação de seus principais construtos teóricos: subjetividade, sentido subjetivo, configuraçáo subjetiva e sujeito.

Para tornar inteligível essa forma como a pessoa organiza a própria experiência, é que se faz heurístico o conceito de subjetividade, tal qual delineado por González Rey (2002, 2004c), enquanto "um sistema constituído por processos simbólicos e de sentido que se desenvolvem na experiência humana” (González Rey, 2004c, p. 78), marcadamente na relação com os outros, comportando, assim, dimensōes individuais e sociais. Em trabalho mais recente, González Rey (2011) afirma que a subjetividade representa uma condição diferenciada da psique na cultura, sendo ela mesma condiçấo necessária para o desenvolvimento da cultura. $\mathrm{O}$ autor afasta-se, assim, da compreensáo de que os indivíduos e suas relaçôes pessoais sejam reflexos dos aspectos formais que balizam, de certa maneira, suas experiências sociais. Isto é, ele assume como condição humana fundamental a produção subjetiva diferenciada de cada pessoa nos mais diversos espaços sociais que integra.

Náo se trata, portanto, de pesquisar as diretrizes institucionais de forma dissociada das pessoas às quais elas se remetem, mas precisamente de buscar entender como essas práticas institucionais repercutem na vida dessas pessoas. Pensando em formas de se pesquisar essas tramas subjetivas, González Rey $(1997,2005)$ elabora a Epistemologia Qualitativa, segundo a qual o conhecimento é concebido 
como um processo de comunicação, singular e impossível de ser apreendido linearmente, pois é tido enquanto uma produção interpretativa do pesquisador. Os desdobramentos metodológicos dessa concepção se voltam para a ênfase na qualidade da relação estabelecida com a pessoa pesquisada, de modo que se torne possível a construção de uma relação com confiança suficiente para que haja uma comunicação autêntica, permeada pela emocionalidade dos envolvidos. Nessa ótica, a qualidade e o rigor da pesquisa não residem na aplicação de instrumentos pré-estabelecidos e rígidos, mas na qualidade da informação construída, mediante flexibilidade para a elaboração dos instrumentos, de modo a adequar a construção dos mesmos ao contexto pesquisado, buscando tecer relações dialógicas comprometidas com os objetivos da pesquisa. Os instrumentos seriam favorecedores dessa relação e não o fundamento da pesquisa. Trata-se de um giro, tal qual concebe o autor, desde uma epistemologia da resposta, para uma epistemologia da construção.

Rompendo com a dicotomia - amiúde explicitada nas teorias tradicionais - entre indivíduo e sociedade, a partir da Teoria da Subjetividade, os fenômenos sociais não se expressam em seu estado puro, mas tem uma significação humana. É precisamente essa produção individual e diferenciada do fenômeno social que se denomina sentido subjetivo (Silva, 2008). Esse conceito representa a unidade dos processos simbólicos e dos processos emocionais, em que um emerge ante a presença do outro, sem ser sua causa (González Rey, 2002). Emergindo na processualidade das relações e das ações humanas, o conceito de sentido subjetivo reside na não exclusão do homem enquanto sujeito de sua ação. Nesse sentido, ele não existe $a$ priori, necessitando da construçáo interpretativa do pesquisador para sua inteligibilidade.

Portanto, não há nenhum fator ou elemento se tomado sem referência à pessoa - que determine em si mesmo como irá influenciar o curso futuro do desenvolvimento da pessoa. Desse modo, os próprios fatores externos vão refratar por meio das vivências emocionais da pessoa (González Rey, 2009a). Nesse sentido, entende-se que a experiência de alta institucional por dois usuários do CAPS, por exemplo, pode ser vivenciada de formas extremamente diferentes por duas pessoas, ainda que recebam a mesma descrição semiológica em termos de transtorno mental. Esse valor emocional peculiar a cada experiência diz respeito a diferentes histórias de vida, crenças, valores e distintas maneiras de se organizar subjetivamente.

Por sua vez, a configuração subjetiva "é uma organização relativamente estável de sentidos subjetivos relacionados com um evento, atividade, ou produção social determinados" (González Rey, 2009 b, p. 218). Não se trata apenas da integração de diferentes sentidos subjetivos, mas também da organização atuante na produção desses sentidos subjetivos. Ou seja, é na vivência do sujeito que elementos da experiência concreta atual entram em contato com configuraçóes subjetivas, culminando na processualidade dos sentidos subjetivos. Nesse sentido, ela diz respeito à unidade do histórico e do atual na organização da subjetividade, pois representa a expressão do vivido como produção subjetiva. Essa idéia é importante, pois rompe com o pensamento linear e organizado da subjetividade em presente, passado e futuro. Nesse caso, falar do passado e do futuro se refere náo a tempos distintos do presente, mas à maneira como esses tempos são subjetivamente produzidos no momento atual. As configuraçóes subjetivas não são, portanto, estruturas rigidamente estabelecidas, mas constituem um sistema envolvido de forma permanente, em relaçóes nas quais uma configuração pode se integrar com elementos de sentido de outra, como consequência do posicionamento do sujeito nos diferentes momentos de sua vida (González Rey, 2004a).

Desse modo, compreender como se dão os processos subjetivos de usuários em processo de alta é buscar compreender não como esse momento é pensado conscientemente, mas sim como ele é vivenciado por eles a partir de suas produçóes de sentido pessoais dentro do espaço social institucional. Extrapola-se, assim, as concepçóes de controle racional do futuro e da certeza objetiva da normalidade, na forma como elas surgiram no pensamento moderno. Concordo com González Rey (2011), ao afirmar que "sem estudar em profundidade e desenvolver o modelo teórico da configuração subjetiva envolvida no transtorno náo poderemos facilitar alternativas que permitam ao sujeito novas produçóes subjetivas" (p. 37). Estudos nessa direção parecem compor uma profícua maneira de refletir sobre os alcances e os limites das açóes estratégicas implementadas nas instituiçóes. Nesse 
sentido, pode alertar para problemas existentes nas formas como as relaçóes pessoais são desenvolvidas a partir dos serviços, apontando alternativas que levem a uma atençáo mais integral e direcionada para o favorecimento da emergência dos usuários enquanto sujeitos de suas próprias vidas. Por sujeito, remete-se à elaboração teórica de González Rey $(2003,2007)$, enquanto a condição da pessoa que se torna capaz de gerar um espaço próprio de subjetivaçáo nos diferentes momentos de sua vida, para além das normas formais estabelecidas, tornando possível um desenvolvimento ativo e diferenciado nos diferentes espaços sociais que constitui. Essa definição não abre mão do caráter contraditório do sujeito, tampouco vislumbra a possibilidade de uma suposta autonomia plena, mas focaliza uma relativa autonomia na produção de ações alternativas mediante confrontação às formas dominantes da organização social.

No contexto aqui abordado, considera-se que o usuário torna-se sujeito de seu próprio tratamento, nos momentos em que ele se coloca de forma ativa, não se submetendo ao rótulo de seu diagnóstico, nem assumindo uma posição passiva com relaçáo aos preceitos técnicos a serem cumpridos no processo de alta. Assim, ele se torna mais potente na criação de alternativas para seu desenvolvimento, produzindo novas possibilidades que não engessam o seu campo de ação no mundo. Desse modo, essa experiência passa a ser o palco de exercícios que favoreçam a promoção de sua saúde, cenário de seu engajamento na vida - o que vai muito além de uma luta travada contra o transtorno mental.

Desse modo, podemos construir uma aproximaçáo conceitual entre os construtos teóricos sujeito e desinstitucionalização. Na medida em que a desinstitucionalização se remete à construção de alternativas à violência institucional (Barros, 1994), visando novas produçóes de sociabilidades e formas de desenvolvimento, podemos pensar que seu trabalho se dá no favorecimento da apropriação das pessoas atendidas enquanto sujeitos, uma vez que se busca favorecer que elas construam alternativas ao próprio desenvolvimento pessoal, com importantes implicaçóes sociais. A busca se daria, então, pela promoção social com vistas à convivência social tolerante com a diferença, criando novas alternativas ao enclausuramento ordinário das formas de existência que acabam sendo banidas do convívio social (Alvarenga e Dimenstein, 2006).
Isso somente se faz possível se a concepção de saúde for modificada, ultrapassando a concepção mecanicista das funçóes orgânicas do modelo hegemônico de saúde (Canguilhem, 2004) dentro do qual a saúde é um atributo que se tem ou não - e considerando-a enquanto a qualidade dos processos de vida (González Rey, 2011). Nessa perspectiva, ela passa a ser entendida como uma expressão integral do desenvolvimento humano, de modo que sua promoção só pode ser entendida como resultado do completo funcionamento da sociedade, de modo que as instituiçōes tenham nela papel fundamental (González Rey, 2004c). Propõe-se, então, concepções mais matizadas, que descrevam o processo de definição e identificação dos problemas da saúde não em categorias meramente descritivas e distanciadas das pessoas que os vivenciam, mas como negociaçóes complexas entre vários atores, com resultados instáveis ao longo do tempo.

Com base no exposto, o estudo da subjetividade emerge enquanto possibilidade teórica para pesquisas no contexto proposto, ao possibilitar a produção de inteligibilidades relacionadas às formas com que complexos processos humanos no âmbito da saúde mental são vivenciados cotidianamente e que náo poderiam ser observados diretamente na cena empírica sem o favorecimento de recursos teóricos. Logicamente, pode-se estudar esses processos a partir de diversos vieses, tais como: a história, aspectos culturais compartilhados e os aspectos biológicos envolvidos. No entanto, pesquisar a subjetividade é precisamente buscar entender como essas mais diversas esferas se integram na vivência da pessoa, em sua produçáo simbólica e emocional no curso do seu desenvolvimento. Possibilita, nesse sentido, a articulaçáo entre as dimensōes da saúde e da educação na vivência de situaçóes concretas em que essas dimensóes estejam intensamente implicadas.

Concordo com González Rey (2011, p. 22), ao afirmar que os processos terapêuticos não são nem conservadores, nem progressistas em abstrato, de modo que eles apenas representam uma opçáo de desenvolvimento da pessoa ao defender uma ética do sujeito que se concretiza no reconhecimento de sua capacidade geradora como processo fundamental da mudança. Dito em outras palavras, "sem a emergência do outro como sujeito do próprio processo terapêutico não 
acontece mudança terapêutica”. Nesse sentido, há que se estar atento para as diferentes formas com que esse sujeito toma forma, a partir de práticas individuais e institucionais.

\section{Conclusões}

Este estudo abordou teoricamente alguns desafios presentes na realidade da assistência em saúde mental no Brasil. Nesse sentido, apresentou as transformaçóes nas concepçōes e práticas no universo da saúde pública no país, que, apesar de seus alcances, acabou por culminar em frequentes e novos quadros de institucionalização dos usuários dos serviços especializados no cuidado em saúde mental. Desse modo, o texto chama a atenção para a necessidade de buscar relaçóes de cuidado que favoreçam o exercício da autonomia por parte das pessoas atendidas e que criem alternativas ao modelo da tutela e da excessiva proteção às pessoas atendidas.

Nessa discussão, a subjetividade emerge enquanto alternativa teórica para estudar o referido contexto, na medida em que busca gerar inteligibilidade sobre as complexas formas com que inúmeros aspectos institucionais e sociais se integram na vivência do sujeito concreto. Isso permite conhecer não apenas os posicionamentos e os sentidos subjetivos singulares de cada pessoa, mas nos permite compreender os alcances e os limites das estratégias institucionais, apontando para transformaçóes necessárias para se conquista uma atenção mais integral e promotora de desenvolvimento aos usuários.

A partir das contribuiçōes teóricas aqui trabalhadas, pode-se pensar que não é por lei que as garantias de transformaçóes plenas idealizadas pela Reforma Psiquiátrica se dáo nas relaçóes humanas cotidianas, já que as produçóes subjetivas atuais extrapolam as intençōes e as formulaçōes abstratas sobre formas de cuidado na saúde. É preciso que se esteja atento para o que acontece no dia-a-dia, percebendo os entraves e dificuldades para que sejam implementadas mudanças substanciais ainda distantes e, também, que se identifique quais são os alcances e potencialidades do que já está sendo feito hoje. Afinal, é isso que nos conduzirá ao que ainda está por vir. Por enquanto, atualmente, muito permanece do antigo modelo vigente e em vários sentidos podemos seguramente dizer que ele continua dominante.

\section{Referências bibliográficas}

- ALVERGA, Alex Reinecke de; DIMENSTEIN Magda (2006). A reforma psiquiátrica e os desafios na desinstitucionalização da loucura. Interface - Comunicaçâo, Saude, Educação 10(20). pp. 299-316.

- AMARANTE, Paulo Duarte de Carvalho (2009). Reforma psiquiátrica e epistemologia. Caderno Brasileiro de Saúde Mental 1(1). pp. 1-7.

- BARROS, Denise Dias (1994). Cidadania versus periculosidade social: a desinstitucionalização como desconstrução do saber. In: Paulo Amarante (Organizador). Psiquiatria Social e Reforma Psiquiátrica. Rio de Janeiro: Editora FIOCRUZ.

- BICHAFF, Regina (2006). O trabalho nos centro de atenção psicossocial: uma reflexáo crítica das práticas e suas contribuiçóes para a consolidação da Reforma Psiquiátrica. Dissertação (Mestrado em Enfermagem). Escola de Enfermagem, São Paulo: Universidade de São Paulo.

- BORTONI-RICARDO, Stella Maria (2008) O professor pesquisador: introdução à pesquisa qualitativa. São Paulo: Parábola.

- BRASIL (2004a). Saúde Mental no SUS: os centros de atenção psicossocial. Brasília: Ministério da Saúde.

- BRASIL (2004b). Saúde Brasil 2004: uma análise da situação de saúde. Brasília: Ministério da Saúde.

- BRASIL (2009). O trabalho do agente comunitário de saúde. Brasília: Ministério da Saúde.

- BRASIL (2010). Relatório Final da IV Conferência Nacional de Saúde Mental-Intersetorial, 27 de junho a 1 de julho de 2010. Brasília: Ministério da Saúde. 
- CAMPOS, Gastão Wagner de Souza (2006) Reflexôes Temáticas sobre Equidade e Saúde: o caso do SUS. Saúde e Sociedade 15 (2). pp. 23-33.

- CAMPOS, Gastão Wagner de Souza; AMARAL, Maria Aparecida (2007). A clínica ampliada e compartilhada, a gestáo democrática e redes de atençáo como referenciais teórico-operacionais para a reforma do hospital. Ciência e Saúde Coletiva 12 (4). pp. 849-859.

- CANGUILHEM, Georges (2004). Escritos sobre la medicina. Buenos Aires: Amorrortu.

- CASTRO, Sueli Aparecida (2009). Caracterização sociodemográfica e clínica das reinternaçóes psiquiátricas no Hospital Santa Tereza de Ribeirão Preto, no periodo de 2006 e 2007. Dissertaçáo (Mestrado em Enfermagem). Escola de Enfermagem de Ribeirão Preto, Universidade de São Paulo, Ribeirão Preto.

- COHN, Amélia; NAKAMURA, Eunice; GUTIERRES, Kellen Alves (2009)."De como o PSF entrecruza as dimensōes pública e privada da vida social”. In Amélia Cohn (Organizadora). Saúde da família e SUS: convergências e dissonâncias. Rio de Janeiro: Beco do Azougue; São Paulo: CEDEC.

- DUTRA, Virgínia Faria Damásio (2011). O cuidado oferecido a pessoas que vivenciaram a experiência da desinstitucionalização. Ciência, Cuidado e Saúde 10 (2). pp. 218-225.

- FLEISCHER, Soraya; TORNQUIST, Carmen Susana; MEDEIROS, Bartolomeu Figueirôa de (2009). "Popularizando o cuidado com a saúde: uma apresentaçáo". In: Soraya Fleischer, Carmen Susana Tornquist e Bartolomeu Figueirôa de Medeiros (organizadores). Saber cuidar, saber contar: ensaios de antropologia e saúde popular. Florianópolis: Editora da UDESC.

- GERSCHMAN, Silvia; SANTOS, Maria Angélica Borges (2006). O Sistema Único de Saúde como desdobramento das políticas de saúde do século XX. RBCS 21(61). pp. 177-227.

- GONZÁLEZ REY, Fernando Luis (1997). Epistemología cualitativa y subjetividad. São Paulo: Educ.

- __ (2002). Sujeito e subjetividade: uma aproximação histórico-cultural. Tradução de Raquel Souza Guzzo. São Paulo: Pioneira Thomson Learning, 2003. Título original: Sujeto y subjetividade.

- _ (2004a). "O sujeito, a subjetividade e o outro na dialética complexa do desenvolvimento humano". In: Albertina Mitjáns Martines; Livia Mathias Simão (organizadoras). O outro no desenvolvimento humano: diálogos para a pesquisa e a prática profissional em psicologia. São Paulo: Pioneira Thomson Learning.

- __ (2004b). O Social na Psicologia e a Psicologia Social: a emergência do sujeito. Petrópolis: Vozes.

- __ (2004c). Personalidade, saúde e modo de vida. Tradução de Flor Maria VidaurreLenz da Silva. São Paulo: Pioneira Thomson Learning. Título original: Personalidad, salud y modo de vida.

- __ (2005a). O valor heurístico da subjetividade na investigaçáo psicológica. In: Fernando Luís González Rey (organizador). Subjetividade, Complexidade e Pesquisa em Psicologia. São Paulo: Pioneira Thomson Learning.

- __ (2007). Psicoterapia, subjetividade e pós-modernidade: uma aproximação histórico-cultural. Tradução de Gullermo Matias Gamucio. São Paulo: Pioneira Thomson Learning. Título original: Psicoterapia, subjetividade y postmodernidad.

- _ _ (2008). O sujeito que aprende: desafios no desenvolvimento do tema da aprendizagem na psicologia e na prática pedagógica”. In: Maria Carmem V. R. Tacca (organizadora). Aprendizagem e trabalho pedagógico. 2 ed. Campinas: Alínea.

- ___ (maio de 2009). La significación de Vygotski para laconsideración de loafectivoenlaeducación: las bases para lacuestión de lasubjetividad. Acesso em: agosto de 2012.: <http://www.latindex.ucr.ac.cr/aie-2009-esp/ aie-2009-es-02.pdf>.

- _ _ (2009b). Epistemología y Ontología: un debate necessário para la Psicología hoy. Diversitas 5 (2). pp. 205-224. Acesso em: 19 de agosto 2012: <http://ojs.usta.edu.co/index.php/diversitas/article/viewFile/6/pdf>.

- ___ (2011). Subjetividade e saúde: superando a clínica da patologia. São Paulo: Cortez. 
- GUERRA, Andréa Máris Campos (2004). Reabilitação psicossocial no campo da reforma psiquiátrica: uma reflexão sobre o controverso conceito e seus possíveis paradigmas. Revista Latinoamericana de Psicopatologia Fundamental 7 (2). pp. 83-96.

- LUCCHESE, Roselma; BARROS, Sônia (2009). A constituição de competências na formação e na prática do enfermeiro em saúde mental. Revista da Escola de Enfermagem da USP 43 (1). pp. 152-160.

- MITJÁNS MARTINES, Albertina (2005). A Teoria da Subjetividade de González Rey: uma expressão do paradigma da complexidade na psicologia. In: Fernando Luís González Rey. Subjetividade, complexidade e pesquisa em psicologia. São Paulo: Pioneira Thomson Learning.

- NASCIMENTO, Pedro Francisco Guedes do (2009). Reprodução, Desigualdades e Políticas Públicas de Saúde: Uma etnografia da construção do desejo de filhos. Tese de Doutorado. Programa de Pós-Graduação de Antropologia. Porto Alegre: Universidade Federal do Rio Grande do Sul.

- PANDE, Mariana Nogueira Rangel; AMARANTE, Paulo Duarte de Carvalho (2011). Desafios para os Centros de Atenção Psicossocial como serviços substitutivos: a nova cronicidade em questáo. Ciência \& Saúde Coletiva 16 (4). pp. 2067-2076.

- PERES, Cássia Regina Fernandes Biffe; CALDAS JÚNIOR, AntonioLuiz; SILVA, Roseli Ferreira da; MARIN, Maria José Sanches (2011). O Agente Comunitário de Saúde frente ao processo de trabalho em equipe: facilidades e dificuldades. Revista da Escola de Enfermagem da USP 45 (4). pp. 905-911.

- PITIÁ, Ana Celeste de Araújo; FUREGATO, Antônia Regina Ferreira (2009). O Acompanhamento Terapêutico (AT): dispositivo de atenção psicossocial em saúde mental. Interface - Comunicação, Saúde, Educação 13 (20). pp. 67-77.

- RAMOS, DéborahKarollyne Ribeiro.; GUIMARÁES, Jacileide; ENDERS, Bertha Cruz (2011). Análise contextual de reinternaçôes frequentes de portador de transtorno mental. Interface - Comunicação, Saúde, Educação 15 (37). pp. 519-527.

- ROSA, Lúcia Cristina dos Santos; LUSTOSA, Amanda Furtado Mascarenhas (2010). Formaçáo profissional do assistente social para atuar na saúde mental: elementos para o debate contemporâneo. Revista Serviço Social \& Realidade 19 (2). pp. 203-218.

- ROTELLI, Franco; LEONARDIS, Ota de; MAURI, Diana. Desinstitucionalização, uma outra via. In: NICÁCIO, F. (org.). Desinstitucionalização, São Paulo: Hucitec, 2001. pp. 17-59.

- SILVA, Giselle de Fátima (2008). Os sentidos subjetivos de adolescentes com câncer. Dissertação (Mestrado em Psicologia). Curso de Pós-graduação em Psicologia do Centro de Ciências da Vida, Campinas: Pontifícia Universidade Católica de Campinas.

- TEIXEIRA JR, Sidnei; KANTORSKI, Luciane Prado; OLSCHOWSKY, Agnes (2009). O Centro de Atenção Psicossocial a partir da vivência do portador de transtorno psíquico. Revista Gaúcha de Enfermagem 30 (3). pp. 453-460. 